\title{
Effects of polyamines on agronomic traits and photosynthetic physiology of wheat under high temperature stress
}

\author{
J.G. JING, S.Y. GUO, Y.F. LI, and W.H. LI+ \\ Key Laboratory of Oasis Eco-Agriculture, Xinjiang Production and Construction Group, Shihezi University, \\ 832003 Shihezi, Xinjiang, China
}

\begin{abstract}
Two spring wheat varieties were used to study alleviating effects of exogenous spermine (Spm) and spermidine (Spd) on agronomic traits and photosynthesis under high temperature treatment (HT). Our results showed that HT significantly decreased grain mass per panicle of heat-resistant variety (XC 6) by $25 \%$ and heat-sensitive variety (XC 31 ) by $32 \%$. After HT, i.e., at $13 \mathrm{~d}$ after flowering, the decrease in net photosynthetic rate of XC $6(38 \%)$ was lower than that of XC $31(53 \%)$; the reason for this was related to XC 6, which could maintain correspondingly normal chlorophyll content (Chl), stomatal conductance $\left(g_{\mathrm{s}}\right)$, transpiration rate $(E)$, and intercellular $\mathrm{CO}_{2}$ concentration. Exogenous Spm and Spd could increase relative water content, Chl, $g_{s}, E$, the maximal quantum yield of PSII photochemistry, effective quantum yield of PSII photochemistry, antenna conversion efficiency, and photochemical quenching coefficient of flag leaves under HT. Our results indicated that the heat resistance of XC 6 is better than that of XC 31 and exogenous Spm and Spd could alleviate the heat injury of photosynthesis of wheat flag leaves.
\end{abstract}

Additional key words: chlorophyll fluorescence parameters; gas exchange; grain-filling period; heat stress; photosynthetic characteristics.

\section{Introduction}

Wheat (Triticum aestivum L.) is one of the main food crops all over the world, and its production is directly related to the issue of food security. The yield potential of wheat is divided into the following three major components: the panicle number per plant, the grain number per panicle, and the grain mass. Grain filling, the final stage of cereal growth, determines the grain mass (Yang et al. 2006). The high temperature during the filling period is the main meteorological disaster in the wheat producing area, and it can cause 10-20\% declines in severe cases (Asseng et al. 2011, Almeselmani et al. 2015, Akter and Islam 2017), which results from the decrease of Chl, weakening of photosynthetic ability, and the significant decrease of grain-filling rate, thousand kernel mass (TKM), and the grain number per panicle (GNP) under high temperature stress (Rane and Nagarajan 2004, Lipiec et al. 2013). Photosynthesis is one of the most sensitive processes to high temperatures in plants, and can be completely inhibited before other physiological functions are inhibited (Chapman et al. 1980, Wang et al. 2000, Makoto and Koike 2007, Luo et al. 2016, Jayakumar and Surendran 2017). Under high temperature stress, Rubisco, a key enzyme of photosynthesis, was inactivated (Allakhverdiev et al. 2008), which affected its ability to assimilate $\mathrm{CO}_{2}$ and significantly reduced net photosynthetic rate $\left(P_{\mathrm{N}}\right)($ CraftsBrandner and Salvucci 2000, Ashraf and Harris 2013). PSII is the most sensitive component to heat in the electron transport chain (Chapman et al. 1980), and high temperature stress can easily inhibit the electron transport, resulting in a decrease in photochemical efficiency. High temperature can damage the structure and function of photosynthetic membranes in chloroplasts, especially PSII, and reduce the excitation energy conversion efficiency of PSII (Martre et al. 2003, Monneveux et al. 2003, Chen and Zhang 2004). The high temperature stress caused chlorophyll (Chl) fluorescence parameters to decrease rapidly, and the reaction center activity of PSII was inhibited (Guo et al. 2000, 2005). Under high temperature, $P_{\mathrm{N}}, E, g_{\mathrm{s}}$, intercellular $\mathrm{CO}_{2}$ concentration $\left(C_{\mathrm{i}}\right)$, the maximal quantum yield of PSII photochemistry $\left(\mathrm{F}_{\mathrm{v}} / \mathrm{F}_{\mathrm{m}}\right)$, antenna conversion

\footnotetext{
Received 22 March 2019, accepted 24 June 2019.

${ }^{+}$Corresponding author; phone: +8615509930607 , fax: +869932057999 , e-mail: 1 wh agr@shzu.edu.cn

Abbreviations: $\mathrm{Chl}$ - chlorophyll content; $C_{\mathrm{i}}$ - intercellular $\mathrm{CO}_{2}$ concentration; $\mathrm{CK}$ - control (normal growth conditions outside the greenhouse); DAF - days after flowering; $\mathrm{DM}$ - dry mass; $E$ - transpiration rate; FM - fresh mass; $\mathrm{F}_{\mathrm{v}} / \mathrm{F}_{\mathrm{m}}-$ maximal quantum yield of PSII photochemistry; $\mathrm{F}_{\mathrm{v}}{ }^{\prime} / \mathrm{F}_{\mathrm{m}}{ }^{\prime}$ - antenna conversion efficiency; GMP - grain mass per panicle; GNP - grain number per panicle; $g_{s}$ - stomatal conductance; HT - artificially simulated high temperature; HT + Spd - artificially simulated high temperature + exogenous application spermidine $\left(1 \mathrm{mM} \mathrm{L}^{-1}\right) ; \mathrm{HT}+\mathrm{Spm}-$ artificially simulated high temperature + exogenous application of spermine $\left(1 \mathrm{mM} \mathrm{L}{ }^{-1}\right)$; MDA - malondialdehyde; PAs - polyamines; $P_{\mathrm{N}}$ - net photosynthetic rate; $\mathrm{q}_{\mathrm{p}}$ - photochemical quenching coefficient; RWC - relative water content; Spd - spermidine; Spm - spermine; TKM - thousand kernel mass; TM - turgid mass; TW - test mass; $\Phi_{\text {PSII }}-$ effective quantum yield of PSII photochemistry.

Acknowledgements: This study was financially supported the Research Fund for the Doctoral Program of the Xinjiang Production and Construction Corps (2016AC027).
} 
efficiency $\left(\mathrm{F}_{\mathrm{v}}{ }^{\prime} / \mathrm{F}_{\mathrm{m}}{ }^{\prime}\right)$, effective quantum yield of PSII photochemistry $\left(\Phi_{\text {PSII }}\right)$, and photochemical quenching coefficient $\left(\mathrm{q}_{\mathrm{p}}\right)$ of four wheat varieties were lower than that in control (CK). Also the adaptability of wheat to heat stress was different between the varieties (Qi et al. 2008). At present, main measures of resistance to the heat injury of wheat during the grain-filling stage are breeding new varieties of heat-resistant crop, irrigating timely and appropriately, etc. (Ainsworth and Ort 2010).

Polyamines (PAs) are organic polycations, which are low molecular-mass nitrogen-containing compounds. They have been described as endogenous plant growth regulators or intracellular messengers that regulate plant growth, development, and responses to abiotic stresses (Bais and Ravishankar 2003, Alcázar et al. 2010, Hussain et al. 2011, Shi and Chan 2014). Zhang et al. (2010) suggested that application of spermidine ( $\mathrm{Spd}, 0.1 \mathrm{mM} \mathrm{L}^{-1}$ ) under conditions of abiotic stress can increase the soluble protein content of leaves and reduce the relative conductivity and malondialdehyde (MDA) content (Zhang et al. 2010). Many researches have reported that polyamine treatment under adverse conditions can maintain high $\mathrm{Chl}$, promote the balance of $\mathrm{O}_{2}{ }^{--}$content, reduce plasma membrane permeability, and maintain the integrity of cell plasma membrane in leaves $\left(1 \mathrm{mM} \mathrm{L}^{-1}\right)$ (Besford et al. 1993, Ha et al. 1998, Song et al. 2012). In addition, PAs were thought to be involved in the regulation of grain development. The polyamine concentration of normal kernels was significantly higher than that of aborting maize kernels (Zea mays L.), and the polyamine concentration was positively correlated with the endosperm nuclei number (Liang and Lur 2002). Yang et al. (2008) found that higher concentrations of Spd [300 $\left.\mathrm{nM} \mathrm{g}^{-1}(\mathrm{FM})\right]$ and spermine [Spm, $\left.240 \mathrm{nM} \mathrm{g}^{-1}(\mathrm{FM})\right]$ promote grain filling and increase the grain mass of rice (Oryza sativa L.). Tan et al. (2009) suggested that low concentrations of Spd [220 nM g-1(FM)] and Spm [180 nM $\left.\mathrm{g}^{-1}(\mathrm{FM})\right]$ and low Spd/putrescine (Put) and Spm/Put ratios may be important physiological causes of the low grainfilling rate and the low grain mass of inferior spikelets in super rice. These studies suggest that PAs are involved in a regulation of the grain development in plants. However, there are few reports about the effect of exogenous polyamines on photosynthetic physiology of wheat under heat stress. Therefore, in the present study, two spring wheat cultivars, which differ in their heat resistance, were used as experimental materials to investigate the effects of exogenous PAs on agronomic traits, photosynthetic characteristics, and chlorophyll fluorescence parameters of flag leaves under high temperature stress. The main objective of the study was to investigate the effect of heat stress on photosynthesis in the two wheat varieties and we also sought to determine whether the photosynthesis of wheat can be regulated by manipulating the PA concentrations under heat stress.

\section{Materials and methods}

Experimental site and design: The experiment was conducted at a research station of Shihezi University, Xinjiang, in northwestern China $\left(45^{\circ} 19^{\prime} \mathrm{N}, 74^{\circ} 56^{\prime} \mathrm{E}\right)$ from
March to July 2018. The soil at the experimental farm is of moderate fertility; readily available $\mathrm{N}, \mathrm{P}$, and $\mathrm{K}$ quantities were $0.058,0.025$, and $0.149 \mathrm{~g} \mathrm{~kg}^{-1}$ respectively. The maximum and minimum temperatures were 36.9 and $9.4^{\circ} \mathrm{C}$, respectively. The diammonium phosphate $(\mathrm{N}$ content was $16.5 \%$, containing $\left.47.5 \% \mathrm{P}_{2} \mathrm{O}_{5}\right), 155 \mathrm{~kg} \mathrm{hm}^{-2}$, was used as base fertilizer; $70,150,80$, and $80 \mathrm{~kg} \mathrm{hm}^{-2}$ urea were applied, at the 3-leaf stage, jointing stage, booting stage, and filling stage (drip fertilization), respectively. The test materials were heat-resistant Triticum aestivum $\mathrm{L}$. variety XC 6 and heat-sensitive variety XC 31 (Li et al. 2017). They have the same both flowering and growth period. The test materials were sown on 24 March and entered the flowering period on 28 May. Before the hightemperature treatment, the plants with the same growth (at the same flowering time) were selected and marked. At $7 \mathrm{~d}$ after flowering (DAF), the shed was kept in the field for $5 \mathrm{~d}$, and the plastic film was put down at 10:00-18:00 $\mathrm{h}$ each day $(20 \mathrm{~cm}$ off the ground for ventilation) to increase the temperature. The temperature inside and outside the shed during the treatment was recorded with an automatic thermometer $(R C-4 H C$, Elitech, China; the thermometer was suspended $15 \mathrm{~cm}$ above the wheat canopy). Fig. 1 shows the temperature changes inside and outside the shed during the treatment. It can be seen that the temperature inside the shed was significantly higher than that outside except for 18:00 h.

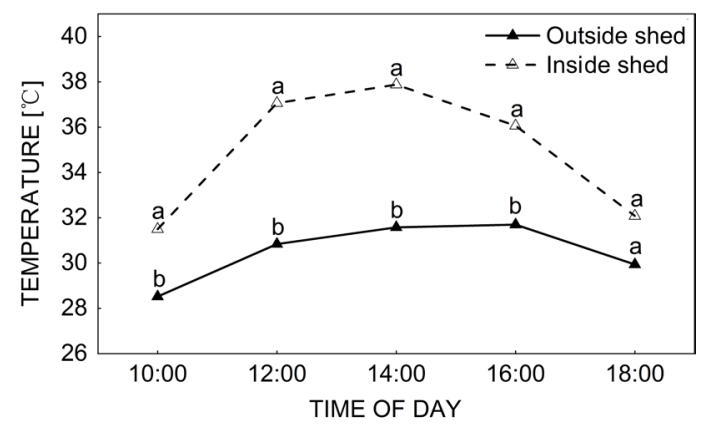

Fig.1. Diurnal change of the average temperature (for $5 \mathrm{~d}$ ) inside and outside the shed during treatment. Values within line chart followed by the same letter are statistically insignificant at the 0.05 level.

The average temperature inside and outside the shed during the treatment was 34.9 and $30.5^{\circ} \mathrm{C}$, respectively, thus the effect of heat stress was achieved.

Spm and Spd were purchased from Sigma with purity $\geq 98$ and $\geq 97 \%$, respectively. The treatments were as follows:

\begin{tabular}{ll}
\hline CK & $\begin{array}{l}\text { control, normal growth conditions outside } \\
\text { the greenhouse } \\
\text { artificially simulated high temperature } \\
\text { artificially simulated high temperature plus } \\
\text { exogenous application of spermidine }\left(1 \mathrm{mM} \mathrm{L} \mathrm{m}^{-1}\right) \\
\text { HT }+ \text { Spd }\end{array}$ \\
HT + Spm & $\begin{array}{l}\text { artificially simulated high temperature plus } \\
\text { exogenous application of spermine }\left(1 \mathrm{~m} \mathrm{~L} \mathrm{~L}^{-1}\right)\end{array}$ \\
\hline
\end{tabular}


Exogenous spraying by PAs started from the day before high temperature treatment and lasted for $5 \mathrm{~d}$. PAs were sprayed on the flag leaves and panicles every day at 8:00 h, each by $20 \mathrm{ml}$ (CK and HT spraying with water).

Agronomic traits: The grain number per panicle (GNP), grain mass per panicle (GMP), and the thousand kernel mass (TKM) were determined according to the method of Li et al. (2017); test mass (TW) was measured using grain moisture tester (GAC-2100AGRI, DICKEY-john, USA)

Relative water content: The fresh mass was immediately recorded after leaf excision (FM). The leaves were left in distilled water for $24 \mathrm{~h}$ and the turgid mass was recorded (TM). The dry mass (DM) was then measured after $48 \mathrm{~h}$ at $80^{\circ} \mathrm{C}$. The relative water content $(\mathrm{RWC})$ was calculated as: $\mathrm{RWC}[\%]=(\mathrm{FM}-\mathrm{DM}) /(\mathrm{TM}-\mathrm{DM}) \times 100$.

Chl content: After being treated by high temperature for $0,5,15,20$, and $25 \mathrm{~d}$, the Chl content in flag leaves was determined by portable Chl meter (SPAD 502, KonicaMinolta, Japan). Thirty leaves were measured for each treatment, and each leaf was measured three times by dividing it into leaf tip, middle leaf, and leaf base; the average value was taken as the SPAD value of the leaf.

Gas exchange: After being treated by high temperature for $0,5,15,20$, and $25 \mathrm{~d}$, the flag leaves with the same growth were selected to measure gas-exchange parameters. The net photosynthetic rate $\left(P_{\mathrm{N}}\right)$, stomatal conductance $\left(g_{\mathrm{s}}\right)$, intercellular $\mathrm{CO}_{2}$ concentration $\left(C_{\mathrm{i}}\right)$, and transpiration rate $(E)$ of the leaves were measured from 10:00-12:00 h using a portable photosynthesis system $(\mathrm{Li}-6400, \mathrm{Li}$-COR Inc., NE, USA) at a light intensity of $1,700 \mu \mathrm{mol}($ photon) $\mathrm{m}^{-2} \mathrm{~s}^{-1}$ under uniform conditions $\left[25-32^{\circ} \mathrm{C}, 400-500\right.$ $\left.\mu \mathrm{mol}\left(\mathrm{CO}_{2}\right) \mathrm{mol}^{-1}\right]$. Nine flag leaves were determined for each treatment.

Chl fluorescence was determined on the same leaves employed for the photosynthesis measurements, using a portable fluorometer (PAM-2100, Walz, Germany). Flag leaves (15) were used for each treatment. The fluorescence kinetic parameters were calculated according to the method of Li et al (2015).

Statistical analysis: Analysis of variance $(A N O V A)$ was performed using SPSS software v. 22.0. Differences between treatments were considered significant at $P<0.05$ according to Duncan's multiple range tests. The figures were plotted using Microsoft Excel 2010 and Origin 2018.

\section{Results}

Agronomic traits: Compared with CK, HT significantly reduced the grain number per panicle (GNP), thousand kernel mass (TKM), test mass (TW), and grain mass per panicle (GMP) of XC 6 by 18, 13, 2, and 25\%, and in XC 31 , by $26,15,3$, and $32 \%$, respectively (Table 1 ), indicating that the heat resistance of XC 6 is better than that of XC 31. The decrease of the GNP and GMP caused by HT was the main reason for the decline of the wheat yield. Compared to HT, HT + Spm significantly increased the GNP, TKM, and GMP of XC 6 by 17, 7, and 19\%, and of XC 31 by 24, 10, and 35\%, respectively. The HT + Spd treatment significantly increased GNP, TKM, and GMP of XC 6 all by 5\%, and in XC 31 by 17, 12, and $32 \%$, respectively, indicating that exogenous Spm and Spd could significantly alleviate the injury to wheat caused by high temperature under HT, and the alleviating effect of Spm was better than that of Spd.

Relative water content and $\mathrm{Chl}$ content: With the grainfilling process, RWC and Chl of flag leaves of the two varieties gradually decreased, and the decrease was slow in the early stage and sharp in the later stage (Fig. 2). Before HT (7 DAF), there was no significant difference in the RWC and Chl of wheat flag leaf between the two varieties at the four treatments, indicating that the water status of plants was consistent. After HT (13 DAF), RWC of XC 6 decreased significantly compared with $\mathrm{CK}$, and that of XC 31 also decreased, but the difference was not significant. The $\mathrm{Chl}$ in flag leaves of the two varieties under HT + Spd was the highest, which was significantly higher than that under Spm and CK, but not significantly

Table 1. Effect of polyamines on agronomic traits of wheat under high temperature stress. Values (means $\pm \mathrm{SE}, n=3$ ) followed by different letters between four different treatments are significantly different according to the Duncan's multiple range tests $(P<0.05)$. $\mathrm{CK}$ - control; HT - high temperature; HT $+\mathrm{Spd}$ - high temperature + spermidine $\left(1 \mathrm{mM} \mathrm{L}^{-1}\right) ; \mathrm{HT}+\mathrm{Spm}$ - high temperature + spermine $\left(1 \mathrm{mM} \mathrm{L}^{-1}\right)$; XC 6 - heat-resistant variety; XC 31 - heat-sensitive variety.

\begin{tabular}{llllll}
\hline Variety & Treatment & Grain number per panicle & Thousand kernel mass $[\mathrm{g}]$ & Test mass $\left[\mathrm{g} \cdot \mathrm{L}^{-1}\right]$ & Grain mass per panicle $[\mathrm{g}]$ \\
\hline XC 6 & CK & $45.07 \pm 0.46^{\mathrm{a}}$ & $45.92 \pm 0.20^{\mathrm{a}}$ & $772.00 \pm 1.06^{\mathrm{a}}$ & $2.29 \pm 0.11^{\mathrm{a}}$ \\
& HT & $37.00 \pm 0.20^{\mathrm{d}}$ & $39.81 \pm 0.30^{\mathrm{d}}$ & $755.67 \pm 3.06^{\mathrm{b}}$ & $1.72 \pm 0.08^{\mathrm{d}}$ \\
& HT + Spm & $43.33 \pm 0.12^{\mathrm{b}}$ & $42.51 \pm 0.38^{\mathrm{b}}$ & $768.33 \pm 4.01^{\mathrm{a}}$ & $2.04 \pm 0.04^{\mathrm{b}}$ \\
& HT + Spd & $39.00 \pm 0.20^{\mathrm{c}}$ & $41.81 \pm 0.15^{\mathrm{c}}$ & $757.33 \pm 2.31^{\mathrm{b}}$ & $1.80 \pm 0.08^{\mathrm{c}}$ \\
XC 31 & CK & $48.33 \pm 0.31^{\mathrm{a}}$ & $46.04 \pm 0.25^{\mathrm{a}}$ & $764.00 \pm 2.06^{\mathrm{a}}$ & $2.04 \pm 0.09^{\mathrm{a}}$ \\
& HT & $35.87 \pm 0.42^{\mathrm{c}}$ & $39.18 \pm 0.34^{\mathrm{d}}$ & $741.33 \pm 1.57^{\mathrm{c}}$ & $1.39 \pm 0.07^{\mathrm{c}}$ \\
& HT + Spm & $44.33 \pm 0.42^{\mathrm{b}}$ & $43.08 \pm 0.13^{\mathrm{c}}$ & $752.67 \pm 2.08^{\mathrm{b}}$ & $1.87 \pm 0.05^{\mathrm{b}}$ \\
& HT + Spd & $42.07 \pm 0.12^{\mathrm{b}}$ & $43.77 \pm 0.40^{\mathrm{b}}$ & $754.00 \pm 2.65^{\mathrm{b}}$ & $1.83 \pm 0.03^{\mathrm{b}}$ \\
\hline
\end{tabular}




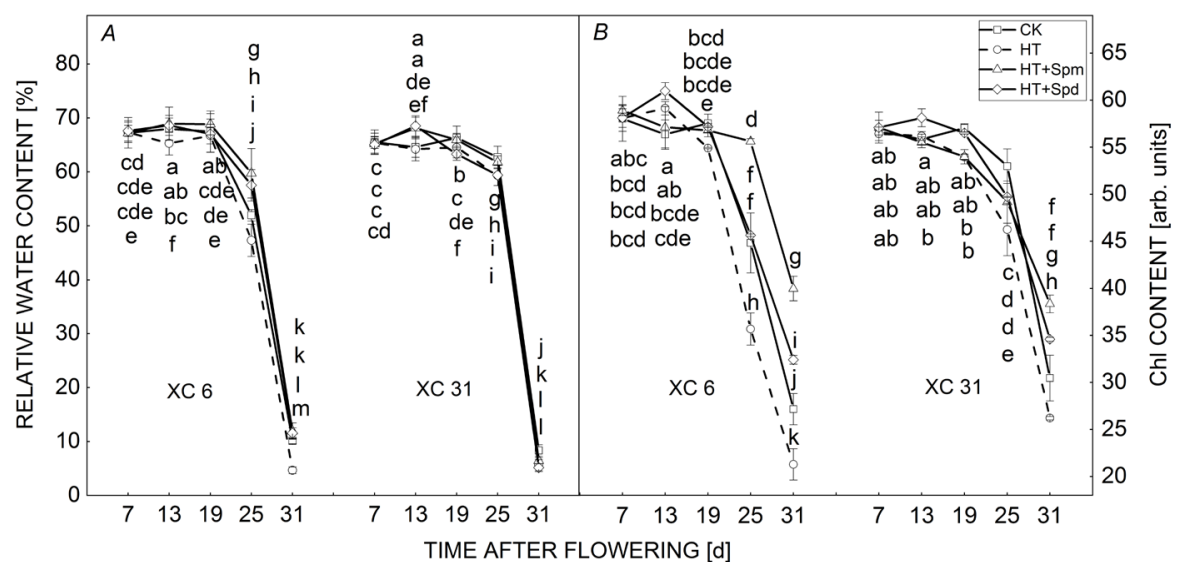

Fig. 2. Changes of the relative water content (RWC) $(A)$ and chlorophyll $(\mathrm{Chl})$ content $(B)$ of flag leaves of two wheat varieties at normal temperature (CK), high temperature (HT), high temperature plus spermine $(\mathrm{HT}+\mathrm{Spm})$, and high temperature plus spermidine $(\mathrm{HT}+\mathrm{Spd})$ during the days after flowering. Bars indicate SD $(n=3)$. The same letters within each panel imply no statistically significant differences. XC 6 - heat-resistant variety; XC 31 - heat-sensitive variety. different from that under HT, which may be due to the selfregulation of plants under heat stress. Compared to HT, $\mathrm{HT}+\mathrm{Spm}$ and HT + Spd significantly increased RWC of the two varieties at $13 \mathrm{DAF}$, indicating that $\mathrm{Spm}$ and Spd had the effect on maintaining RWC of wheat flag leaf under heat stress. At $31 \mathrm{DAF}$, the $\mathrm{Chl}$ in flag leaves of the two varieties under HT $+\mathrm{Spm}$ was the highest followed by $\mathrm{HT}+\mathrm{Spd}$, and both were significantly higher than that under $\mathrm{CK}$ and $\mathrm{HT}$, indicating that the alleviating effect of exogenous PAs on the Chl degradation under heat stress was a continuous process.

Photosynthetic characteristics: With the progress of grain filling, the $P_{\mathrm{N}}$ and $g_{\mathrm{s}}$ of flag leaves of the two varieties gradually decreased, the $C_{\mathrm{i}}$ increased, and the $E$ first increased but declined in the late stage (Fig. 3), indicating that the decrease of $P_{\mathrm{N}}$ at the late filling stage was not led by stomatal limitation. Under HT treatment, the $P_{\mathrm{N}}$ of the two varieties declined significantly at 13,19 , and $25 \mathrm{DAF}$, although the highest decrease occurred at $13 \mathrm{DAF}$; XC 6 decreased by $38 \%$, and XC 31 decreased by $53 \%$. The decline of $g_{\mathrm{s}}$ was different in the two varieties under $\mathrm{HT}$; for $\mathrm{XC} 6$, it decreased significantly at 13,25 , and $31 \mathrm{DAF}$, while for XC 31, the significant decrease occurred at 25 and 31 DAF. The $C_{\mathrm{i}}$ of flag leaves of XC 6 was significantly reduced by $15 \%$ at the $13 \mathrm{DAF}$, but that of XC 31 did not decrease significantly after HT, which was contrary to $E$ of the two varieties. The $E$ of XC 31 was significantly lowered by $11 \%$ at 13 DAF after HT, while $E$ of $\mathrm{XC} 6$ was not significantly reduced; this difference might be related to the self-regulation of wheat under HT. Chl fluorescence parameters: With the progress of grain

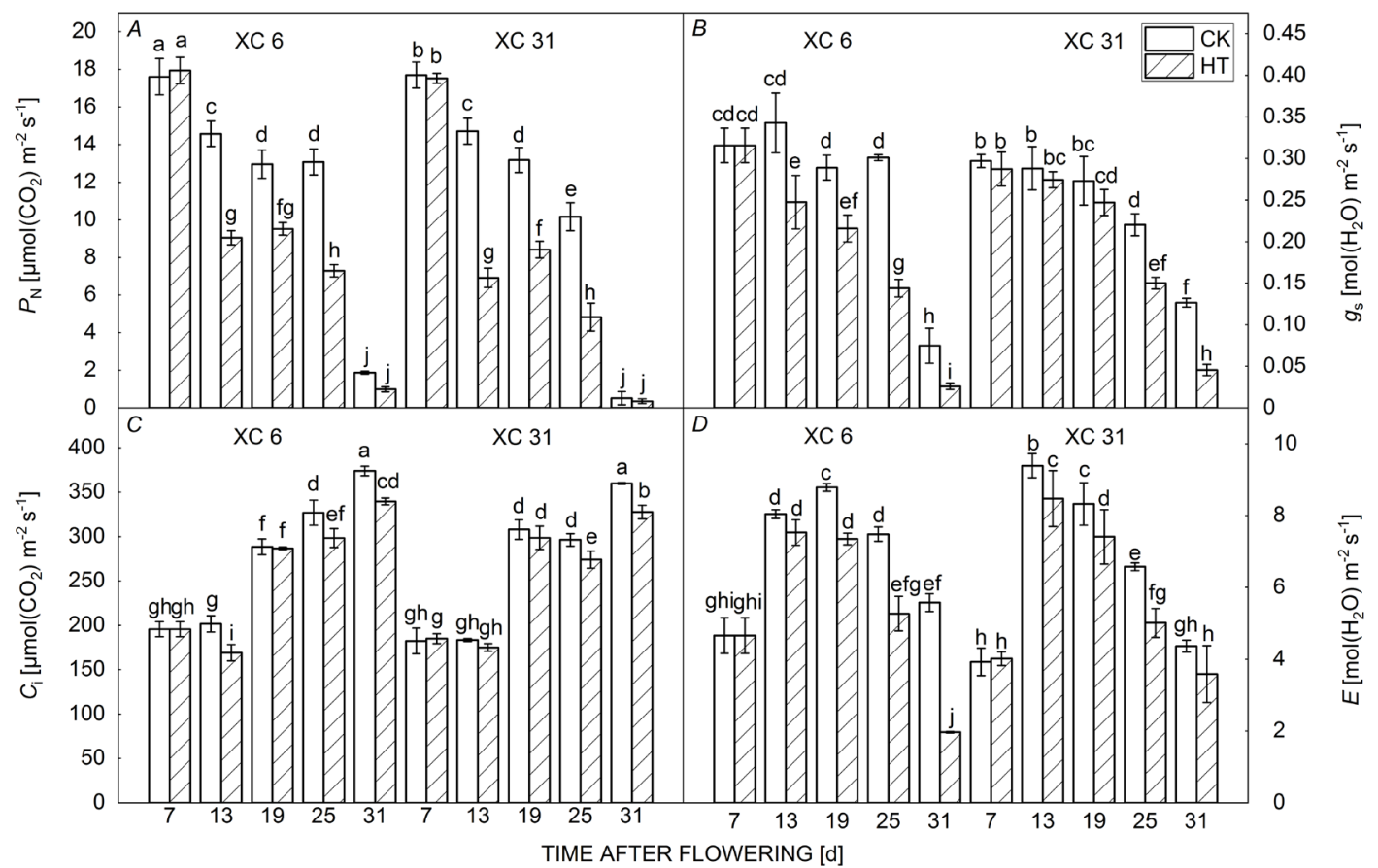

Fig. 3. Changes in the net photosynthetic rate $\left(P_{\mathrm{N}}\right)(A)$, stomatal conductance $\left(g_{\mathrm{s}}\right)(B)$, intercellular $\mathrm{CO}_{2}$ concentration $\left(C_{\mathrm{i}}\right)(C)$, and transpiration rate $(E)(D)$ of flag leaves of two wheat varieties at normal temperature $(C K)$ and high temperature (HT) during the days after flowering. Bars indicate SD $(n=3)$. The same letters within each panel imply no statistically significant differences. XC 6 - heatresistant variety; XC 31 - heat-sensitive variety. 
filling, $\mathrm{F}_{\mathrm{v}} / \mathrm{F}_{\mathrm{m}}, \Phi_{\text {PSII }}, \mathrm{F}_{\mathrm{v}}{ }^{\prime} / \mathrm{F}_{\mathrm{m}}{ }^{\prime}$, and $\mathrm{q}_{\mathrm{p}}$ of flag leaves of the two varieties showed a dropping trend, which slowly decreased in the early stage and then sharply decreased in the later stage (Fig. 4). After HT, the $\mathrm{F}_{\mathrm{v}} / \mathrm{F}_{\mathrm{m}}$ of flag leaves was significantly lower than that of $C K$, although the $F_{v} / F_{m}$ decreased to a lesser extent in $\mathrm{XC} 6$ than that in $\mathrm{XC} 31$ at 13 DAF. The $\Phi_{\text {PSII }}$ and $\mathrm{F}_{\mathrm{v}}{ }^{\prime} / \mathrm{F}_{\mathrm{m}}{ }^{\prime}$ of $\mathrm{XC} 6$ were not significantly different from $\mathrm{CK}$ in the early stage of HT, while for $\mathrm{XC} 31, \Phi_{\mathrm{PSII}}$ and $\mathrm{F}_{\mathrm{v}}{ }^{\prime} / \mathrm{F}_{\mathrm{m}}{ }^{\prime}$ decreased first and then increased briefly in the early stage of HT. The $\mathrm{q}_{\mathrm{p}}$ of XC 31 was significantly lower than that of $\mathrm{CK}$ after HT, and in $\mathrm{XC} 6$, it was not significantly different from CK at $19 \mathrm{DAF}$.

Effects of exogenous Spm on photosynthesis: With the course of grain filling, $P_{\mathrm{N}}$ of the two varieties went down first, then went up and then went down again, and $g_{\mathrm{s}}$ and $E$ increased first and then decreased, while $C_{\mathrm{i}}$ has been on the rise under HT (Fig. 5). Compared to HT, HT $+\mathrm{Spm}$ promoted $P_{\mathrm{N}}$ of the flag leaves significantly at 13, 19, and 25 DAF. The highest increase in XC 6 and XC 31 occurred at 19 and $25 \mathrm{DAF}$, increasing by 22 and $109 \%$, respectively. $\mathrm{HT}+\mathrm{Spm}$ also significantly increased $g_{\mathrm{s}}$ and $E$ of the flag leaf of XC 6 at 13, 19, 25, and $31 \mathrm{DAF}$ and in XC 31 at 13 and $31 \mathrm{DAF}$. It is worth mentioning that compared to HT, $\mathrm{HT}+$ Spm elevated $P_{\mathrm{N}}$ of XC 31 significantly at $19 \mathrm{DAF}$, which may be related to that $\mathrm{HT}+\mathrm{Spm}$ significantly increased the $g_{\mathrm{s}}$ and $E$ at $13 \mathrm{DAF}$, which could reduce leaf surface temperature, thus maintaining the physiological function of PSII after high temperature stress (13 DAF) in the late filling stage.

Effects of exogenous Spd on photosynthesis: Compared to HT, $P_{\mathrm{N}}, g_{\mathrm{s}}, C_{\mathrm{i}}$, and $E$ of the flag leaves of two varieties increased differently under HT + Spd (Fig. 5). With the progress of grain filling, $P_{\mathrm{N}}$ of XC 6 decreased slowly, while for XC 31, it increased first and then decreased. Besides, $g_{\mathrm{s}}$ and $E$ of the two varieties increased first and then decreased, and $C_{\mathrm{i}}$ increased gradually with the progress of grain filling. At $13 \mathrm{DAF}$, compared to HT, difference in $E$ of XC 6 was not significant under $\mathrm{HT}+\mathrm{Spd}$, but $E$ of XC 31 was significantly lower, and $P_{\mathrm{N}}$ of two varieties significantly increased by 72 and $179 \%$, respectively, but decreased significantly at 19 DAF. The $g_{\mathrm{s}}$ and $E$ of the two varieties reached the peak at $19 \mathrm{DAF}$, and were significantly higher than that of HT. While $P_{\mathrm{N}}$ was significantly lower than it was at $13 \mathrm{DAF}$, which further illustrated that the photosynthetic system of flag leaves was in disorder at 13 DAF.

Effects of exogenous Spm on Chl fluorescence parameters: $\mathrm{F}_{\mathrm{v}} / \mathrm{F}_{\mathrm{m}}, \Phi_{\mathrm{PSII}}, \mathrm{F}_{\mathrm{v}}{ }^{\prime} / \mathrm{F}_{\mathrm{m}}{ }^{\prime}$, and $\mathrm{q}_{\mathrm{p}}$ of the flag leaves of two varieties under HT + Spm were higher than that at HT in the whole growth period (Fig. 6), indicating that the exogenous application of Spm could effectively increase the Chl fluorescence parameters under HT in the early stage of grain filling, and the most significant increase occurred at 19 DAF.

Effects of exogenous Spd on Chl fluorescence parameters: $\mathrm{F}_{\mathrm{v}} / \mathrm{F}_{\mathrm{m}}, \Phi_{\mathrm{PSII}}, \mathrm{F}_{\mathrm{v}}{ }^{\prime} / \mathrm{F}_{\mathrm{m}}{ }^{\prime}$, and $\mathrm{q}_{\mathrm{p}}$ of the flag leaves of two varieties under HT + Spd were higher than that at HT in the whole growth period, and with the course of grain filling, all of them tended to decline, then increase, and declined again (Fig. 6). At 13 DAF, there was no

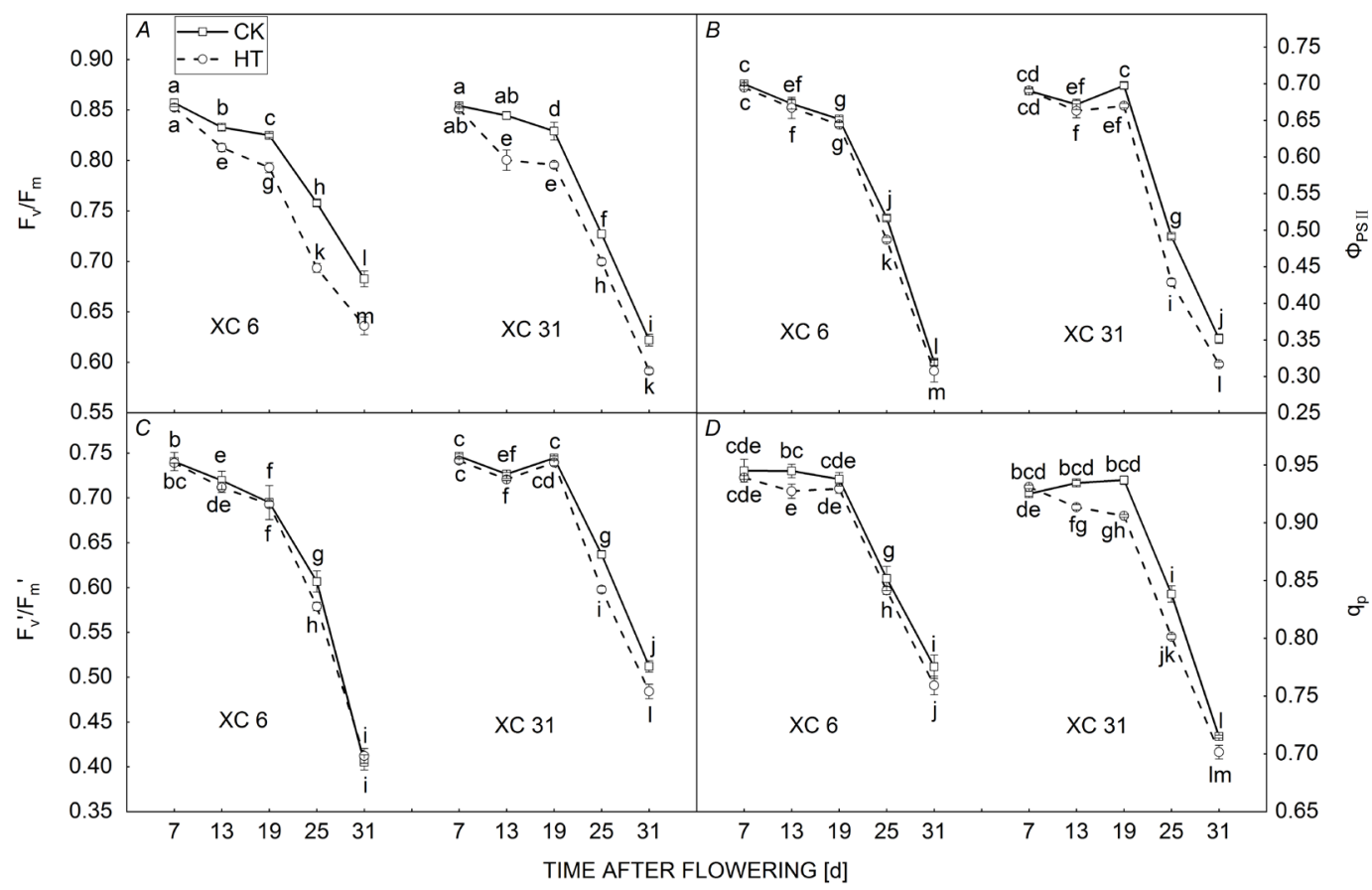

Fig. 4. Changes in the maximal quantum yield of PSII photochemistry $\left(\mathrm{F}_{\mathrm{v}} / \mathrm{F}_{\mathrm{m}}\right)(A)$, effective quantum yield of PSII photochemistry $\left(\Phi_{\mathrm{PSII}}\right)(B)$, antenna conversion efficiency $\left(\mathrm{F}_{\mathrm{v}}{ }^{\prime} \mathrm{F}_{\mathrm{m}}{ }^{\prime}\right)(C)$, and photochemical quenching coefficient $\left(\mathrm{q}_{\mathrm{p}}\right)(D)$ of flag leaves of two wheat varieties at normal temperature $(\mathrm{CK})$ and high temperature (HT) during the days after flowering. Bars indicate $\mathrm{SD}(n=3)$. The same letters within each panel imply no statistically significant differences. XC 6 - heat-resistant variety; XC 31 - heat-sensitive variety. 


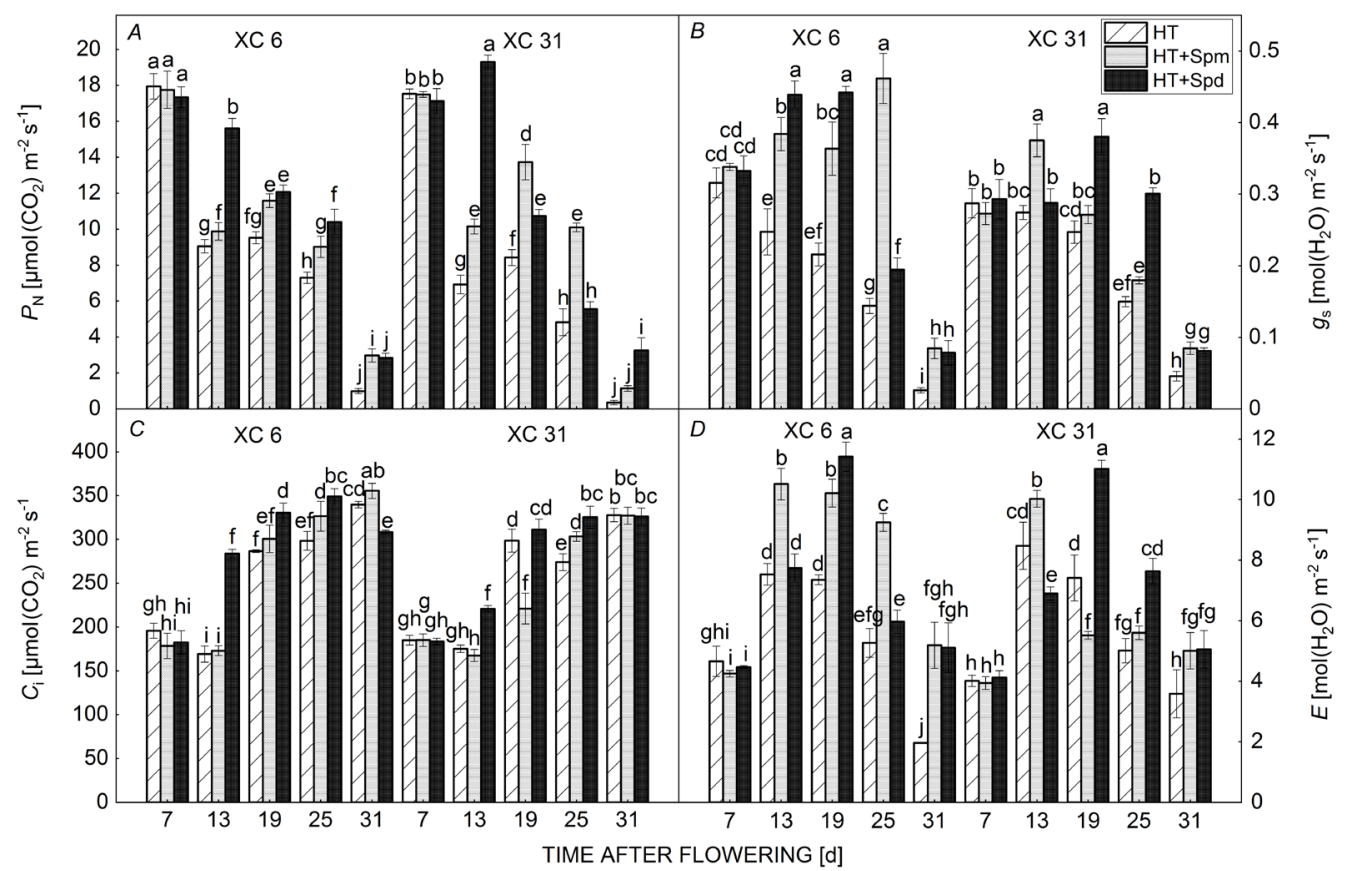

Fig. 5. Changes in the net photosynthetic rate $\left(P_{\mathrm{N}}\right)(A)$, stomatal conductance $\left(g_{\mathrm{s}}\right)(B)$, intercellular $\mathrm{CO}_{2}$ concentration $\left(C_{\mathrm{i}}\right)(C)$, and transpiration rate $(E)(D)$ of flag leaves of two wheat varieties at high temperature $(\mathrm{HT})$, high temperature plus spermine $(\mathrm{HT}+\mathrm{Spm})$, and high temperature plus spermidine $(\mathrm{HT}+\mathrm{Spd})$ during the days after flowering. Bars indicate $\mathrm{SD}(n=3)$. The same letters within each panel imply no statistically significant differences. XC 6 - heat-resistant variety; XC 31 - heat-sensitive variety.

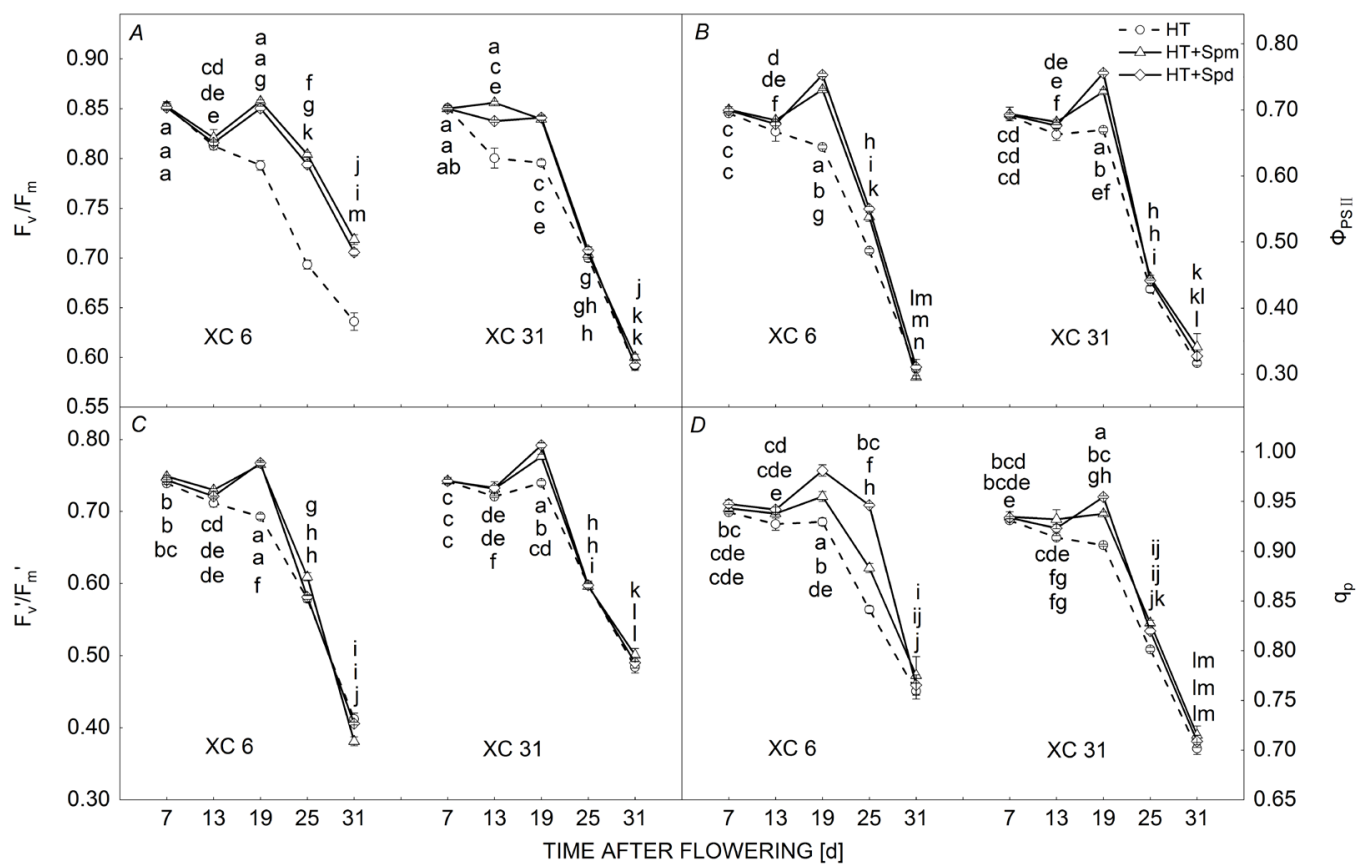

Fig. 6. Changes in maximal quantum yield of PSII photochemistry $\left(\mathrm{F}_{\mathrm{v}} / \mathrm{F}_{\mathrm{m}}\right)(A)$, effective quantum yield of PSII photochemistry $\left(\Phi_{\mathrm{PSII}}\right)(B)$, antenna conversion efficiency $\left(\mathrm{F}_{\mathrm{v}}{ }^{\prime} / \mathrm{F}_{\mathrm{m}}{ }^{\prime}\right)(C)$ and photochemical quenching coefficient $\left(\mathrm{q}_{\mathrm{p}}\right)(D)$ of flag leaves of two wheat varieties at high temperature $(\mathrm{HT})$, high temperature plus spermine $(\mathrm{HT}+\mathrm{Spm})$, and high temperature plus spermidine $(\mathrm{HT}+\mathrm{Spd})$ during the days after flowering. Bars indicate SD $(n=3)$. The same letters within each panel imply no statistically significant differences. XC 6 - heatresistant variety; XC 31 - heat-sensitive variety.

significant difference in the $\mathrm{F}_{\mathrm{v}} / \mathrm{F}_{\mathrm{m}}$ of $\mathrm{XC} 6$ between HT and $\mathrm{HT}+\mathrm{Spd}$, while the $\mathrm{F}_{\mathrm{v}} / \mathrm{F}_{\mathrm{m}}$ of XC 31 under HT + Spd was significantly higher than that under HT, indicating that under HT, exogenous spraying of Spd could immediately alleviate the damage of high temperature stress on the photosynthetic apparatus of the flag leaves in $\mathrm{XC} 31$. 
The highest the increase of $\mathrm{F}_{\mathrm{v}} / \mathrm{F}_{\mathrm{m}}, \Phi_{\text {PSII }}, \mathrm{F}_{\mathrm{v}}{ }^{\prime} / \mathrm{F}_{\mathrm{m}}{ }^{\prime}$, and $\mathrm{q}_{\mathrm{p}}$ was reached at $19 \mathrm{DAF}$, which was higher than that under HT + Spm, showing that the application of exogenous Spm and Spd under HT could effectively protect the photosynthetic system under high temperature stress, but the effect of exogenous application of Spd at the beginning of stress was better than that of exogenous spraying by Spm.

\section{Discussion}

Agronomic traits: In this study, it was found that HT significantly reduced the GNP, TKM, TW, and GMP of the two wheat varieties. Compared with CK, HT significantly reduced GNP of XC 6 by $18 \%$ and of XC 31 by $26 \%$, and also decreased GMP of XC 6 by $25 \%$ and of XC 31 by $32 \%$, indicating that the heat resistance of XC 6 is better than that of XC 31, and the decrease of GMP caused by HT was the main reason for the decrease of wheat yield. Previous studies have suggested that PAs were involved in the regulation of grain development (Liang and Lur 2002, Yang et al. 2008, Tan et al. 2009). The results of this study showed that both HT + Spm and HT + Spd significantly increased the GNP, TKM, and GMP of the two wheat varieties compared with HT.

Relative water and $\mathrm{Chl}$ content: Previous study has shown that high temperature stress resulted in chloroplast structure destruction and Chl degradation in plant leaves, and exogenous PAs could rapidly enter the intact chloroplasts to participate in the protection of photosynthetic apparatus under adverse conditions (Li et al. 2015). Exogenous addition of Spm can effectively improve antioxidant enzyme activity, and restore chloroplast function under salt stress (Shu et al. 2013). The results of our study showed that $\mathrm{Chl}$ content at 13 and 31 DAF of both varieties was the highest under $\mathrm{HT}+\mathrm{Spd}$ and $\mathrm{HT}+\mathrm{Spm}$, respectively, significantly higher than under HT, indicating that exogenous PAs can alleviate the Chl degradation under heat stress. This may be due to differences in the content of endogenous PAs between the four treatments, so the next step of this study is to measure endogenous PAs for a further analysis. After $13 \mathrm{DAF}, \mathrm{HT}$ significantly decreased the RWC of XC 6 compared with $\mathrm{CK}$, and that of XC 31 also decreased, but the difference was not significant. $\mathrm{XC}$ 6 might respond more quickly to heat stress.

Photosynthetic characteristics: Previous studies found that the photosynthetic characteristics of different wheat varieties after HT were significantly different (Zhang et al. 2008, Jiang et al. 2014). Our study found that after HT (13 DAF), $P_{\mathrm{N}}$ of flag leaf of XC 6 decreased significantly by $38 \%$ compared with $\mathrm{CK}$, and for XC 31 , it significantly decreased by $53 \%$, which further proved that XC 6 has stronger heat resistance, and $\mathrm{XC} 31$ is sensitive to heat stress (Li et al. 2017). $P_{\mathrm{N}}$ of the two varieties decreased (13 DAF) and then increased (19 DAF) under HT, which may be related to the self-regulation of plants. Exogenous addition of Spd significantly increased the $P_{\mathrm{N}}$ of XC 6 and XC 31 by 72 and $179 \%$, respectively, compared to HT. Liu et al. (2006) and Zhou et al. (2006) observed that exogenous PAs increased the $P_{\mathrm{N}}$ of maize under abiotic stress. Our study found that exogenous Spm significantly increased the $P_{\mathrm{N}}$ of the flag leaf of XC 31 by $47 \%$ under HT. Li et al. (2007) reported that exogenous Spd can increase $g_{s}$ of cucumber leaves under abiotic stress. In our study, it was found that exogenous Spd under high temperature stress significantly increased $g_{\mathrm{s}}$ of the flag leaf of XC 6 by $36 \%$. Spraying Spm under HT significantly increased $g_{\mathrm{s}}$ of flag leaves of two varieties by 54 and $37 \%$, respectively, and $E$ increased by 39 and $18 \%$, respectively. This indicates that the important reason for Spm maintaining the higher $P_{\mathrm{N}}$ of flag leaves under high temperature stress is that it could increase $g_{\mathrm{s}}$ and $E$ to reduce the surface temperature of the flag leaf and protect the photosynthetic system. Compared with CK, HT significantly increased $C_{\mathrm{i}}$ of XC 6 , similar to the result of Wang et al. (2003), but not of XC 31, which may be caused by their different heat resistance. The study also found that at 19 and $25 \mathrm{DAF}, \mathrm{HT}+\mathrm{Spm}$ made $P_{\mathrm{N}}$ of XC 31 significantly higher than that of HT and HT + Spd, which may be related to the fact that HT + Spm made $E$ significantly higher than that of HT and HT + Spd at 13 DAF. Higher $E$ could reduce the surface temperature of flag leaves to protect the photosynthetic system.

Chl fluorescence: The effects of high temperature stress on photosynthetic systems are multifaceted, not only affecting photosynthetic electron transport and photosynthetic phosphorylation, but also causing damage to photosynthetic apparatus. $\mathrm{F}_{\mathrm{v}} / \mathrm{F}_{\mathrm{m}}$ is an indicator of photosynthetic efficiency of PSII (Wang et al. 2009). HT mainly damages PSII of plants (Krause and Santarius 1975). Under adverse conditions, the photochemical efficiency directly determines $P_{\mathrm{N}}$ of leaves (Harbinson et al. 1989). The study found that after HT (13 DAF), $F_{v} / F_{m}$ of XC 6 and XC 31 was significantly lower than that of CK. $\Phi_{\mathrm{PSII}}$ and $\mathrm{F}_{\mathrm{v}}{ }^{\prime} / \mathrm{F}_{\mathrm{m}}{ }^{\prime}$ under $\mathrm{HT}$ were the lowest among the four treatments. The study also found that, compared to HT (13 DAF), exogenous Spm significantly increased $\mathrm{F}_{\mathrm{v}} / \mathrm{F}_{\mathrm{m}}$ of both varieties, but for exogenous $\mathrm{Spd}$, the increase was significant only in XC 6. After HT, among the four treatments, $\Phi_{\text {PSII }}$ of two varieties treated with $\mathrm{Spm}$ was the highest, $\mathrm{F}_{\mathrm{v}}{ }^{\prime} / \mathrm{F}_{\mathrm{m}}{ }^{\prime}$ of $\mathrm{XC} 6$ under Spm treatment was the largest, and $\mathrm{q}_{\mathrm{p}}$ in plants sprayed Spd was the highest. This further illustrated that PAs have a certain alleviating effect on the Chl fluorescence characteristics of wheat under high temperature stress. Compared with $\mathrm{CK}$, exogenous application of Spm and Spd under heat stress had a better effect on the photosynthetic physiology, which may be related to the fact that normal temperature in Xinjiang was higher than would be optimal for wheat grain filling. So we intend to add also Spm and Spd treatments under the normal temperature for further study.

Conclusion: There was a difference in the tolerance of wheat flag leaves to high temperature. The tolerance of $\mathrm{XC} 6$ was higher than that of XC 31. High temperature stress significantly decreased GMP, and significantly inhibited $P_{\mathrm{N}}$ of wheat flag leaves. Exogenous Spm and Spd could alleviate the heat injury to photosynthetic apparatus of wheat flag leaves. 


\section{References}

Ainsworth E.A., Ort D.R.: How do we improve crop production in a warming world? - J. Plant Physiol. 154: 526-530, 2010.

Akter N., Islam M.R.: Heat stress effects and management in wheat. A review. - Agron. Sustain. Dev. 37: 37-46, 2017.

Alcázar R., Planas J., Saxena T. et al.: Putrescine accumulation confers drought tolerance in transgenic Arabidopsis plants over-expressing the homologous Arginine decarboxylase 2 gene. - Plant Physiol. Bioch. 48: 547-552, 2010.

Allakhverdiev S.I., Kreslavski V.D., Klimov V.V. et al.: Heat stress: an overview of molecular responses in photosynthesis.Photosynth. Res. 98: 541-550, 2008.

Almeselmani M., Deshmukh P.S., Sairam R.K.: High temperature stress tolerance in wheat genotypes: role of antioxidant defence enzymes. - Acta Agron. Hung. 57: 1-14, 2015.

Ashraf M., Harris P.J.C.: Photosynthesis under stressful environments: An overview. - Photosynthetica 51: 163-190, 2013.

Asseng S., Foster I., Turner N.C.: The impact of temperature variability on wheat yields. - Glob. Change Biol. 17: 997-1012, 2011.

Bais H.P., Ravishankar G.A.: Synergistic effect of auxins and polyamines in hairy roots of Cichorium intybus L. during growth, coumarin production and morphogenesis. - Acta Physiol. Plant. 25: 193-208, 2003.

Besford R.T., Richardson C.M., Campos J.L., Tiburcio A.F.: Effect of polyamines on stabilization of molecular complexes in thylakoid membranes of osmotically stressed oat leaves. Planta 189: 201-206, 1993.

Chapman K.S.R., Berry J.A., Hatch M.D.: Photosynthetic metabolism in bundle sheath cells of the $\mathrm{C}_{4}$ species Zea mays: Sources of ATP and NADPH and the con bution of photosystem II. - Arch. Biochem. Biophys. 202: 330-342, 1980.

Chen G.X., Zhang R.X.: [Study on PSII characteristics of photosynthetic function decline in wheat flag leaves.] - Sci. Agr. Sin. 37: 36-42, 2004. [In Chinese]

Crafts-Brandner S.J., Salvucci M.E.: Rubisco activase constrains the photosynthetic potential of leaves at high temperature and $\mathrm{CO}_{2}$. - P. Natl. Acad. Sci. USA 97: 13430-13435, 2000.

Guo P.G., Li R.H.: [Effects of high temperature stress at night on photosynthetic apparatus in rice leaves] - J. Integr. Plant Biol. 42: 673-678, 2000. [In Chinese]

Guo T.C., Fang B.T., Wang C.Y. et al.: [Effects of water regulation on chlorophyll fluorescence kinetic parameters and yield of wheat flag leaves.] - Agr. Res. Arid Areas 23: 6-10, 2005. [In Chinese]

Ha H.C., Sirisoma N.S., Kuppusamy P. et al.: The natural polyamine spermine functions directly as a free radical scavenger. - P. Natl. Acad. Sci. USA 95: 11140-11145, 1998.

Harbinson J., Genty B., Baker N.R.: Relationship between the quantum efficiencies of photosystems I and II in pea leaves. Plant Physiol. 90: 1029-1034, 1989.

Hussain S.S., Ali M., Ahmad M., Siddique K.H.: Polyamines: natural and engineered abiotic and biotic stress tolerance in plants. - Biotechnol. Adv. 29: 300-311, 2011.

Jayakumar M., Surendran U.: Intercropping and balanced nutrient management for sustainable cotton production. - J. Plant Nutr. 40: 632-644, 2017.

Jiang W.W., Yin Y.P., Wang Z.L. et al.: [Effects of nitrogen fertilizer topdressing and later transfer on yield and flag leaf physiological characteristics of wheat under post-anthesis high temperature stress.] - Acta Agron. Sin. 40: 942-949, 2014. [In Chinese]

Krause G.H., Santarius K.A.: Relative thermostability of chloroplast envelope. - Planta 127: 285-299, 1975.
Li J., Gao X.H., Guo S.R. et al.: [Effects of exogenous spermidine on photosynthesis of cucumber seedlings under salt stress.] Chin. J. Ecol. 26: 1595-1599, 2007. [In Chinese]

Li X., Gong B., Xu K.: [Effects of exogenous spermidine on endogenous hormone and chloroplast ultrastructure of ginger leaves under high temperature stress.] - Sci. Agr. Sin. 48: 120-129, 2015. [In Chinese]

Li Z.F., Zhang D.H., Wang Z.Q. et al.: [Evaluation of heat tolerance of spring wheat varieties in Xinjiang.] - J. Triticeae Crop 11: 1497-1502, 2017. [In Chinese]

Liang Y.L., Lur H.S.: Conjugated and free polyamine levels in normal and aborting maize kernels. - Crop Sci. 42: 1217-1224, 2002.

Lipiec J., Doussan C., Nosalewicz A., Kondracka K.: Effect of drought and heat stresses on plant growth and yield: a review. Int. Agrophys. 27: 463-477, 2013.

Liu J., Zhou Y.F., Zhang W.H. et al.: [Effects of exogenous polyamines on chloroplast-bound polyamine levels and photosynthesis in maize under salt stress.] - Acta Bot. Bor.Occident. Sin. 2: 254-258, 2006. [In Chinese]

Luo H.H., Zhang Y.L., Zhang W.F.: Effects of water stress and rewatering on photosynthesis, root activity, and yield of cotton with drip irrigation under mulch. - Photosynthetica 54: 65-73, 2016.

Makoto K., Koike T.: Effects of nitrogen supply on photosynthetic and anatomical changes in current-year needles of Pinus koraiensis seedlings grown under two irradiances. Photosynthetica 45: 99-104, 2007.

Martre P., Porter J.R., Triboi E.: Modeling grain nitrogen accumulation and protein composition to understand the sink/ source regulations of nitrogen remobilization for wheat. Plant Physiol. 133: 1959-1967, 2003.

Monneveux P., Pastenes C., Reynolds M.P.: Limitations to photosynthesis under light and heat stress in three highyielding wheat genotypes. - J. Plant Physiol. 160: 657-666, 2003.

Qi X.L., Hu L., Dong H.B. et al.: [Photosynthetic characteristics of different wheat varieties under the action of strong light and high temperature.] - Acta Agron. Sin. 34: 2196-2201, 2008. [In Chinese]

Rane J., Nagarajan S.: High temperature index - For field evaluation of heat tolerance in wheat varieties. - Agr. Syst. 79: 243-255, 2004.

Shi H., Chan Z.: Improvement of plant abiotic stress tolerance through modulation of the polyamine pathway. - J. Integr. Plant Biol. 56: 114-121, 2014.

Shu S., Yuan L.Y., Guo S.R. et al.: Effects of exogenous spermine on chlorophyll fluorescence, antioxidant system and ultrastructure of chloroplasts in Cucumis sativus L. under salt stress. - Plant Physiol. Bioch. 63: 209-216, 2013.

Song Y.J., Diao Q.N., Qi H.Y.: [Advances in research on polyamine metabolism and plant stress resistance.] - Chin. Vegetab. 1: 36-42, 2012. [In Chinese]

Tan G.L., Zhang H., Fu J. et al.: [Post-anthesis changes in concentrations of polyamines in superior and inferior spikelets and their relation with grain filling of super rice.] Acta Agron. Sin. 35: 2225-2233, 2009. [In Chinese]

Wang B.G., Liu Y.H., Wu X.H. et al.: [Relationship between high temperature resistance and chlorophyll fluorescence parameters of green bean varieties.] - J. Zhejiang Agr. Sci. 1: 461-462, 2009. [In Chinese]

Wang C.Y., Zhu Y.J., Xia G.J. et al.: [Changes of photosynthesis parameters of wheat flag leaves under high temperature and their correlation analysis.] - Acta Agric. Bor.-Sin. 18: 8-11, 2003. [In Chinese]

Wang S.W., Xu C.C., Bai K.Z. et al.: Comparison of photo- 
inhibition characteristics of two different genotypes of wheat.J. Integr. Plant Biol. 42: 1300-1303, 2000.

Yang J.C., Cao Y.Y., Zhang H. et al.: Involvement of polyamines in the post-anthesis development of inferior and superior spikelets in rice. - Planta 228: 137-149, 2008.

Yang J.C., Zhang J.H., Liu K. et al.: Abscisic acid and ethylene interact in wheat grains in response to soil drying during grain filling. - New Phytol. 171: 293-303, 2006.

Zhang C.M., Zou Z.R., Huang Z. et al.: [Effects of exogenous spermidine on photosynthesis of different tomato seedlings under drought stress.] - Agr. Res. Arid Areas 28: 182-187, 2010. [In Chinese]

Zhang L.P., Jing Q., Dai Y.B. et al.: [Effects of temperature and light intensity on photosynthetic characteristics and senescence of flag leaves of different quality types of wheat.] Chin. J. Appl. Ecol. 19: 311-316, 2008. [In Chinese]

Zhou G.X., Guo S.R., Wang S.P.: [Effects of exogenous polyamines on photosynthetic characteristics and membrane lipid peroxidation of cucumber seedlings under hypoxia stress.] Chin. Bull. Bot. 23: 341-347, 2006. [In Chinese]

(C) The authors. This is an open access article distributed under the terms of the Creative Commons BY-NC-ND Licence. 